\title{
Antibiotics for sore throat to prevent rheumatic fever: Yes or No? How the Cochrane Library can help
}

§ See related article page 747

W

ith the winter season just around the corner you anticipate numerous patient enquiries and visits related to the use of antibiotics for the common cold and associated morbidities. One day a 45-year-old woman, a recent immigrant from India, presents to your office with sore throat and fever of 2 days' duration. In India her male cousin acquired rheumatic fever following a sore throat for which he did not receive antibiis otics. She is now worried about getting rheumatic fever herself and insists on having antibiotics prescribed.

You decide to search the Cochrane Library (www .cochrane.org/reviews/clibintro $. h t m)$, to which your practice group subscribes, for evidence of the effectiveness of antibiotics for sore throat to prevent rheumatic fever. You log on and open Issue 3, 2004, and in the search box you enter the terms "(sore throat) and (antibiotics) and (rheumatic fever) and (primary care)" (Fig. 1). You find the review "Antibiotics for sore throat." ${ }^{\prime}$ By printing the review, you obtain 41 pages of text with an abstract including "reviewers' conclusions." (A lay summary of the review is available at Informed Health Online (www.informed healthonline.org//item.aspx?tabid $=8 \&$ review $=000023)$, and that Web site has a direct link to the abstract of the review in the Cochrane Library.) After open- ing the review, you click on "outline" at the top of the tool bar, and the outline appears on the left of your screen. At the bottom left you click on "metaview graphs" and the outcome "Incidence of acute rheumatic fever within 2 months" is displayed as a forest plot. You notice that the authors have used an odds ratio (0.30, $95 \%$ confidence interval [CI] 0.20 to 0.45 ) as the default statistic for this outcome (Fig. $2)$. In the forest plot, no weights are assigned to the studies in which no outcomes in both the treatment and control groups occurred. Not being a gambler, you have a poor understanding of odds ratios. You are more familiar with the

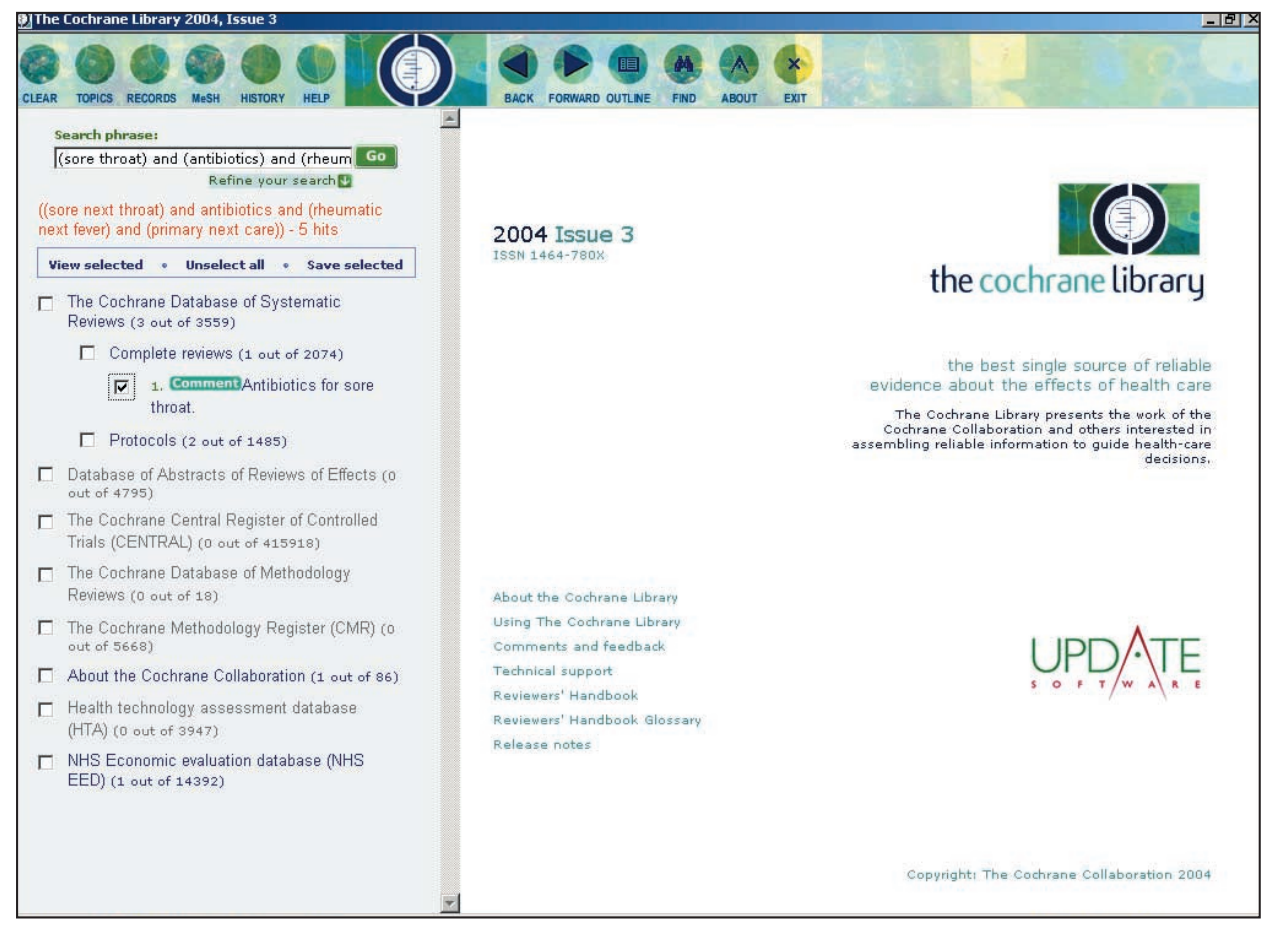

Fig. 1: Opening page of the Cochrane Library, Issue 3, 2004. The screen will look like this after you enter your search terms and click on "The Cochrane Database of Systematic Reviews" and then "Complete reviews." The review "Antibiotics for sore throat" has been ticked. The opening page also gives you a link to the Reviewer's Handbook, which is an extensive document of how Cochrane Reviews are conducted and provides detailed information on statistical methods.

For a trial use of the Cochrane Library, please refer to www.cmaj.ca for details. 


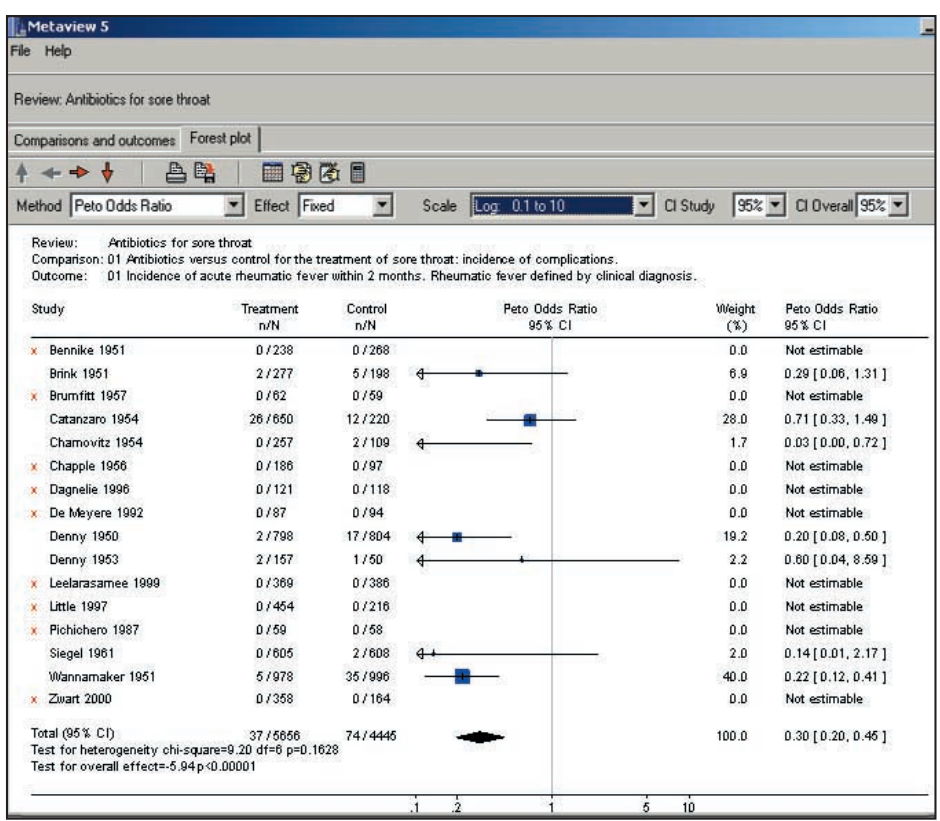

Fig. 2: Forest plot of the outcome "Incidence of acute rheumatic fever within 2 months $^{\prime \prime}{ }^{1}$ with odds ratio as the statistic. Results are displayed as odds ratios (see the "Method box" to the left). The vertical line of 1 (unity) under the heading "Peto Odds Ratio" indicates no difference in outcomes between the treatment and control groups. The point estimate of the effect size for each study is illustrated by a box (the size of the box varies according to the sample size of the trial). The $95 \%$ confidence interval $(\mathrm{Cl})$ is depicted as a horizontal line on each side of the box. If the horizontal line does not cross 1 (unity), the finding of that study is statistically significant. Each study is assigned a weight, but if there are no outcomes in both the treatment and control groups, no weight is assigned. The diamond at the bottom of the display is the typical (summary) odds ratio and includes the $95 \% \mathrm{Cl}(0.30,95 \% \mathrm{Cl} 0.20$ to $0.45 ; p<0.00001)$. The diamond is located to the left of 1 , which indicates a statistically significant reduction in the adverse outcome. The test for heterogeneity is not significant ( $p=0.1628)$.

\section{Table 1: Calculation of relative risk (risk ratio), odds ratio, risk difference and number needed to treat*}

The results of a clinical trial can be displayed as a $2 \times 2$ table:

\begin{tabular}{lccc} 
Group & Event & No event & Total \\
\hline Intervention & $\mathrm{a}$ & $\mathrm{b}$ & $\mathrm{a}+\mathrm{b}$ \\
Control & $\mathrm{c}$ & $\mathrm{d}$ & $\mathrm{c}+\mathrm{d}$
\end{tabular}

Risk ratio (relative risk) $(\mathrm{RR})=$ risk of event in intervention group / risk of event in control group $=(\mathrm{a} /[\mathrm{a}+\mathrm{b}]) /(\mathrm{c} /[\mathrm{c}+\mathrm{d}])$.

Odds ratio $(\mathrm{OR})=$ odds of event in intervention group / odds of event in control group $=(\mathrm{a} / \mathrm{b}) /(\mathrm{c} / \mathrm{d})=\mathrm{ad} / \mathrm{bc}$.

Risk difference $(\mathrm{RD})=$ risk of event in intervention group - risk of event in control group $=a /(a+b)-c /(c+d)$.

Number needed to treat $(\mathrm{NNT})=1 / \mathrm{RD}=$ number needed to treat to avoid 1 adverse outcome.

*Adapted from the Cochrane Reviewers' Handbook, available in the Cochrane Library (www.cochrane.org/reviews/clibintro.htm). terms "relative risk," "absolute risk difference" ("risk difference" as it is called in the Cochrane Library) and "number needed to treat" and you decide to use those statistics instead (Table 1). This is easily done. When you change the statistics in the "methods" box to relative risk, you find similar results as those for odds ratio (because the outcome of rheumatic fever is rare, the odds ratio and relative risk will be numerically close).

In the methods section of the review you note that the reviewers made extensive efforts to identify eligible studies, and it would seem inappropriate to discard important information because there were no outcomes in both the treatment and control groups (indicating that there may be no advantage of the intervention under study). When you change the statistics to risk difference $(-0.01,95 \%$ CI -0.02 to -0.01), all of the studies are weighted (Fig. 3). A risk difference of $1 \%$ between the treatment and the control group of having the adverse outcome may convey a different message than an odds ratio of 0.30 would. By taking the inverse of the risk difference (in this case $1 / 0.01$ ) you obtain the number needed to treat $(100,95 \%$ CI 50 to 100$)$. It tells you that, on average, you need to treat 100 patients with sore throat with antibiotics to avoid 1 case of rheumatic fever. You note that the test for heterogeneity is statistically significant $(p<$ 0.00001), which indicates that the effect size varies between studies, making the results less robust. In addition, you note that, in the studies conducted in the 1990s, there were no cases of rheumatic fever among 2484 patients enrolled. The reviewers performed a secondary analysis in which they separated studies published before and after 1975 and found no cases of rheumatic fever after 1975. As expected, there is no heterogeneity among the studies published after 1975 , as 
there were no adverse outcomes in any group.

You summarize your findings in Table 2, and you have good evidence not to prescribe antibiotics for sore throat to prevent rheumatic fever in your patient. There may be subpopulations in Canada in whom the base rate of rheumatic fever is very high, as is the case in Australian Aborigines living in poor socioeconomic conditions, and therefore the use of antibiotics for sore throat is justified.

\section{Arne Ohlsson \\ Kathie Clark}

Arne Ohlsson is Professor in the Departments of Paediatrics, Obstetrics and Gynaecology, and Health Policy Management and Evaluation, University of Toronto, Toronto, Ont., and the Department of Clinical Epidemiology and Biostatistics, McMaster University, Hamilton, Ont. He is Director of the Canadian Cochrane Network and Centre. Kathie Clark is Co-director of the Canadian Cochrane Network and Centre, Faculty of Health Sciences, McMaster University, Hamilton, Ont.

\section{Reference}

1. Del Mar CB, Glasziou PP, Spinks AB. Antibiotics for sore throat [Cochrane review]. In: The Cochrane Library, Issue 3. Chichester (UK): John Wiley and Sons; 2004.

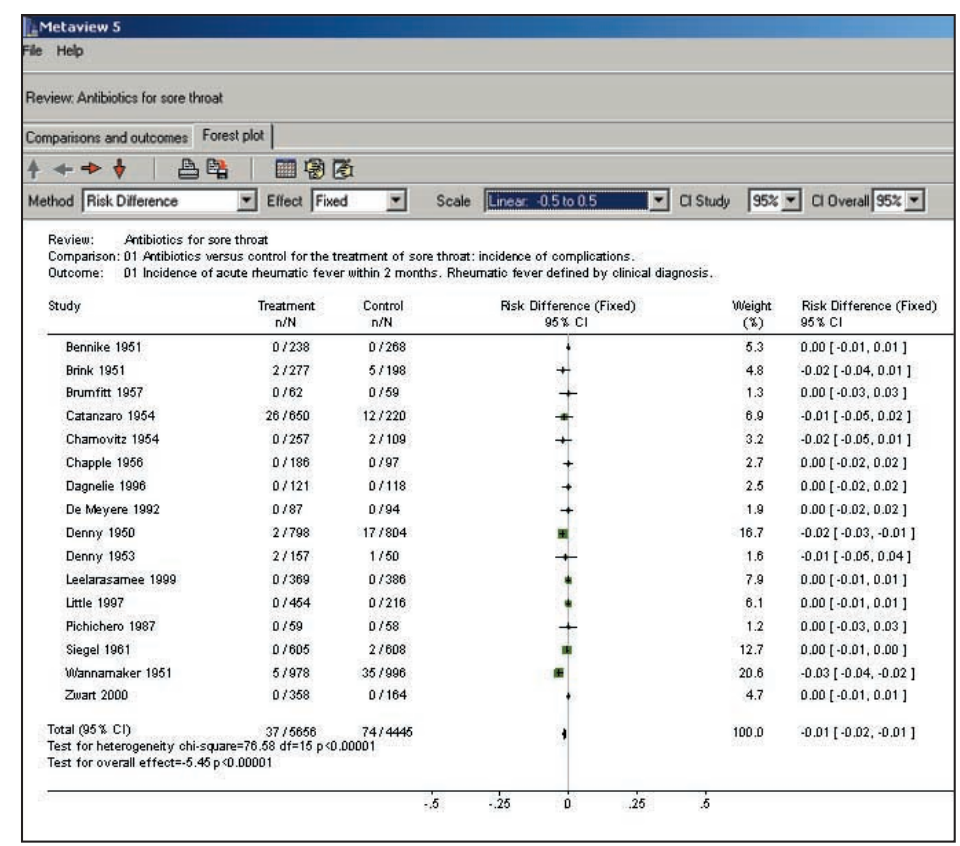

Practice

Fig. 3: Forest plot of the outcome "Incidence of acute rheumatic fever within 2 months" ${ }^{\prime \prime}$ with risk difference as the statistic. Same comparison and outcome as in Fig. 2, but in the "Method box" the statistical test has been changed to "risk difference," and the scale has been changed to " -0.5 to $0.5^{\prime \prime}$ to make it easier to visualize the results of individual studies. The vertical line under the heading "Risk difference (fixed)" represents no difference in outcomes between the treatment and control groups (unity is now 0). All studies have now been assigned a weight. The risk difference is $-0.01(95 \% \mathrm{Cl}-0.02$ to $-0.01), p<0.0001$. The test for heterogeneity is statistically significant $(p<0.0001)$, which indicates that there is study heterogeneity with regard to the effect size.

\section{Table 2: Summaries of the Cochrane systematic review "Antibiotics for sore throat"}

\begin{tabular}{|c|c|c|}
\hline Outcome of interest & Authors' conclusions ${ }^{1}$ & Your observations \\
\hline $\begin{array}{l}\text { Acute rheumatic fever }(n=10101): \text { NNT }=100 \\
(95 \% \mathrm{Cl} 50 \text { to } 100)\end{array}$ & \multirow{9}{*}{$\begin{array}{l}\text { "Antibiotics confer relative benefits in the } \\
\text { treatment of sore throat. However the absolute } \\
\text { benefits are modest. Protecting sore throat } \\
\text { sufferers against suppurative and non-suppurative } \\
\text { complications in modern Western society can be } \\
\text { achieved only by treating with antibiotics many } \\
\text { who will derive no benefit. Antibiotics shorten the } \\
\text { duration of symptoms by a mean of one day about } \\
\text { half way through the illness (the time of maximal } \\
\text { effect, and about sixteen hours overall)." } \\
\text { "Acute rheumatic fever is common among people } \\
\text { living in some parts of the world (Australian } \\
\text { Aborigines living in poor socioeconomic } \\
\text { conditions, for example), and antibiotics may be } \\
\text { justified to reduce the complication of acute } \\
\text { rheumatic fever in these settings." } \\
\text { "For other settings where rheumatic fever is rare, } \\
\text { there is a balance to be judged between modest } \\
\text { symptom reduction and the hazards of } \\
\text { antimicrobial therapy. Since ninety percent of } \\
\text { patients are free of symptoms by one week (in } \\
\text { both groups), the absolute benefit of antibiotics } \\
\text { at this time and beyond is vanishingly small." }\end{array}$} & \multirow{9}{*}{$\begin{array}{l}\text { You note that } 10 \text { of the } 16 \text { studies } \\
\text { included for the outcome of rheumatic } \\
\text { fever were conducted in the } 1950 \text { s. The } \\
\text { rate of rheumatic fever in the control } \\
\text { group of those studies varied from } 0 \% \text { to } \\
5 \% \text {. In the studies published in the } 1990 \text { s } \\
\text { and later, there were no cases of } \\
\text { rheumatic fever in both the treatment and } \\
\text { control groups ( } n=2484 \text { ). When using } \\
\text { the odds ratio, the results of those studies } \\
\text { were not given a weight and did not } \\
\text { contribute to the point estimate for the } \\
\text { outcome of rheumatic fever. The } \\
\text { inclusion in the same meta-analysis of } \\
\text { the old and new studies when using the } \\
\text { risk difference (with different rates of the } \\
\text { outcome) probably explains the } \\
\text { statistically significant heterogeneity } \\
\text { noted. There was no statistically } \\
\text { significant heterogeneity among the } \\
\text { studies published after } 1975 \text {. }\end{array}$} \\
\hline $\begin{array}{l}\text { Otitis media within } 14 \text { days (all studies) }(n= \\
3760): \text { NNT }=50(95 \% \text { Cl } 50 \text { to } 100)\end{array}$ & & \\
\hline $\begin{array}{l}\text { Otitis media within } 14 \text { days (studies conducted } \\
\text { after } 1975)(n=1923): \mathrm{RD}=-0.01(95 \% \mathrm{Cl} \\
-0.02 \text { to } 0.00), \mathrm{NS}\end{array}$ & & \\
\hline & & \\
\hline $\begin{array}{l}\text { Symptoms of } \\
\text { NNT }=14(95\end{array}$ & & \\
\hline $\begin{array}{l}\text { Symptom of fever on c } \\
\text { NNT }=17(95 \% \mathrm{Cl} 10\end{array}$ & & \\
\hline ay $3(n=911)$ : & & \\
\hline $14 \mathrm{~d}(n=2387)$ : NS & & \\
\hline nephritis within & & \\
\hline
\end{tabular}

Note: $n=$ number of participants enrolled in trials, NNT = number needed to treat to avoid 1 adverse outcome, $\mathrm{Cl}=$ confidence interval, NS $=$ nonsignificant $(p>0.05)$. 